\title{
Vection Is Unaffected by Circadian Rhythms
}

\author{
Masaki Ogawa1, Hiroshi Ito' ${ }^{1}$, Takeharu Seno ${ }^{1,2,3^{*}}$ \\ ${ }^{1}$ Faculty of Design, Kyushu University, Fukuoka, Japan \\ ${ }^{2}$ Institute for Advanced Study, Kyushu University, Fukuoka, Japan \\ ${ }^{3}$ Research Center for Applied Perceptual Science, Kyushu University, Fukuoka, Japan \\ Email: ${ }^{*}$ seno@design.kyushu-u.ac.jp
}

Received 27 February 2015; accepted 14 March 2015; published 19 March 2015

Copyright (C) 2015 by authors and Scientific Research Publishing Inc.

This work is licensed under the Creative Commons Attribution International License (CC BY).

http://creativecommons.org/licenses/by/4.0/

(c) (i) Open Access

\begin{abstract}
We examined the effect of circadian rhythms on self-motion perception (vection). We measured the strength of vection (i.e. latency, duration, and magnitude of vection) every three hours from 9 AM to 9 PM. The results showed that vection was similar at all times measured. Thus, we concluded that vection was unaffected by circadian clock.
\end{abstract}

\section{Keywords}

\section{Self-Motion, Vection, Circadian Rhythms, Day and Night, Visual Perception, Time}

\section{Introduction}

Exposure to a field of visual motion that mimics the retinal flow produced by locomotion typically induces a compelling self-motion illusion, which can be referred to as "vection" (Fischer \& Kornmüller, 1930). Many studies have investigated the most and least effective stimulus attributes for inducing vection. These include traditional vection studies, conducted in the 1970s, to more recent reports from the early 2000s (for reviews see Dichgans \& Brandt, 1978; Howard, 1982; Riecke et al., 2011). Among this body of research, the earliest studies quickly established that the wider the vection stimulus, the stronger the induced vection (e.g. Brandt, Dichgans, \& Koenig, 1973; Held, Dichigans, \& Bauer, 1975; Lestienne, Soeching, \& Berthoz, 1977).

Vection can be affected by proprioception and cognition. For example, Sasaki et al. (2012) reported that upward vection could be enhanced by positive sounds (e.g., the sound of a baby laughing). Additionally, physical burdens (e.g., wearing heavy iron clogs) have been found to inhibit vection (Seno, Abe, \& Kiyokawa, 2013) while alcohol consumption can facilitate vection (Seno \& Nakamura, 2013). Vection also varies depending on age (Shirai, Seno, \& Morohashi, 2013; Shirai et al., 2014; Haibach, Slobounov, \& Newell, 2009).

In addition to the above-mentioned internal factors, vection is also highly affected by environmental factors.

\footnotetext{
${ }^{*}$ Corresponding author.
} 
For example, the altitude of the experimental environment can alter vection strength, and hypoxia can inhibit vection (Nishimura et al., 2014). Moreover, the posture of participants, i.e., the orientation of their body, can differentiate vection strength (e.g. Nakamura \& Shimojo, 1998; Seno, 2014). Vection can be modified by the micro-gravity (Young \& Shelhamer, 1990; Mueller et al., 1994; Allison et al., 2012) and by different social environments. The characteristics of an audience viewing a vection experiment can also inhibit vection (Seno, 2013a). Finally, (background) music can enhance vection strength (Seno, 2013b).

A key environmental factor that has received little attention in vection research is time. To the best of our knowledge, no studies have examined whether vection varies between day and night. This is a possibility because other perceptual and cognitive phenomena are known to vary with the time of day (e.g. Aschoff \& Daan, 2009; Kuriyama et al., 2003). Aschoff and Daan (2009) reported that distinct mechanisms are involved in longterm (hours) and short-term (seconds) time perception (Aschoff \& Daan, 2009). In their experiment, participants lived for several weeks in an isolated room without any time cues, and were asked to estimate the length of an hour by pressing a key on a computer keyboard. Their estimated intervals positively correlated with the duration of wake time of the day. In addition, the researchers observed two peaks in the estimated length of the hours in each day. These data suggest that the sleep-wake cycle regulates long-term time perception.

The endogenous circadian clock also can affect short-term time perception. Pöppel and Giedke (1970) found a diurnal variation of approximately 10 seconds in the time perception of participants who were living according to their normal daily routines (Kuriyama et al., 2003; Morofushi, Shinohara, \& Kimura, 2001; Nakajima et al., 1998; Pöppel \& Giedke, 1970). In the morning, estimated time was longer than actual time, and in the evening, estimated time was shorter than actual time. Additionally, several studies have found a significant negative correlation between estimated time and core body temperature, i.e., participants with a higher core body temperature tend to underestimate the passage of time (Kuriyama et al., 2003; Aschoff, 1984; Aschoff, 1998; Aschoff \& Daan, 2009). This indicates that the circadian oscillator might affect short-term time perception through diurnal variation of body temperature. Interestingly, Bougard et al. (2011) reported that the circadian rhythms could affect body sway in certain conditions. As body sway and vection are thought to be highly related (Palmisano et al., 2014), a relationship between vection and the circadian rhythms seems likely.

Based on the abovementioned facts, we hypothesized that vection could be modulated by the circadian clock (circadian rhythms) such that vection strength differed between the day and night. Furthermore, we anticipated that sleepiness, which is directly related to the circadian rhythms, could also affect vection strength. In a separate experiment, we reported that vection strength was positively correlated with subjective sleepiness (Ogawa et al., submitted). Specifically, participants who were sleep deprived for approximately 24 hours perceived vection as being stronger compared with those who had a normal sleep schedule.

Human performance can be dramatically modified by sleep deprivation (see Bonnet, 2002, for a review). For example, binocular depth inversion can be enhanced by sleep deprivation (Schmeider et al., 1996). Araujo et al. (2013) examined the relationship between visual performance and hours of sleep in public school students. They found that going to sleep early and having a regular sleep schedule contributed to superior visuospatial performance. Additionally, visual short-term memory has been found to decline after sleep deprivation (Chee \& Chuah, 2007).

The way that sleepiness is regulated by the circadian rhythms can be described according to the "two process model” (Daan, Beersma, \& Borbely, 1984). In this model, an unknown sleep-inducible substance accumulates during wakefulness and rapidly decreases during sleeping. The periodical accumulation of this substance associated with the sleep-wake cycle is a homeostatic process. However, the circadian clock in the brain is known to modify the effect of sleep induction such that sleepiness is reduced during the subjective day and enhanced during the subjective night. In this way, sleepiness appears to be determined by the interaction between circadian and homeostatic processes.

As mentioned above, we hypothesized that vection would be affected by circadian clock. Our hypothesis had two components. The first was that vection would be altered by specific environmental factors. We considered time, i.e. the circadian rhythms to be one of the most important environmental factors ${ }^{1}$. The second was that vection would be affected by subjective sleepiness (Ogawa et al., submitted). As sleepiness is influenced by the circadian clock, we hypothesized that vection would be modulated by the circadian clock, i.e., vection strength

\footnotetext{
${ }^{1}$ Some expert researchers of the circadian clock may think that the circadian clock is both internal and external factors of our human perception. However, in this study, we wanted to define it as an "environmental factor". We thought that this can change for each individual researcher and was totally dependent on in which level we should place the distinction between the environment and human beings.
} 
would differ between the morning, midday, and night. To examine this hypothesis, we measured vection strength every three hours from 9 AM to 9 PM. We hoped to uncover new information about the way in which circadian rhythms affect visual perception.

\section{Methodology}

\subsection{Ethics Statement}

Our experiments were pre-approved by the Ethics Committee of Kyushu University, and written informed consent was obtained from each participant prior to testing.

\subsection{Participants}

Ten adult volunteers participated in this experiment (age range: 21 - 31 years; four males and six females). Participants were graduate students, undergraduate students, or post-doctoral researchers. All participants reported normal vision, had no history of vestibular system disease, provided their informed consent, and were unaware of the purpose of the experiment. All ten participants had previously experienced vection in a laboratory setting (either as part of another vection experiment or as observers of vection demonstrations in psychology classes).

\subsection{Stimulus and Apparatus}

We generated and controlled our experimental stimuli using a personal computer (MacBookPro, MD101J/A; Apple) with a plasma display (3D Viera, 65 inch, Panasonic, $1920 \times 1080$ resolution with a $60-\mathrm{Hz}$ refresh rate). The experiment was conducted in a dark chamber.

All the stimuli were created using OpenGL. Optic flow displays consisted of 1240 randomly positioned dots per frame with projected global dot motion that simulated forward self-motion. These self-motion displays were created by positioning 16,000 dots at random inside a simulated cube (length $20 \mathrm{~m}$ ), and moving the observer's viewpoint to simulate forward self-motion at a rate of $20 \mathrm{~m} / \mathrm{s}$. The mean luminances of the background and the dots were $0.0 \mathrm{~cd} / \mathrm{m}^{2}$ and $26.4 \mathrm{~cd} / \mathrm{m}^{2}$, respectively. The stimulus duration was $40 \mathrm{~s}$. The stimuli subtended 100 deg (horizontal) $\times 81$ deg (vertical) of visual angle at a viewing distance of $57 \mathrm{~cm}$. As dots disappeared off the edge of the screen, they were replaced at the far depth plane (thereby creating an endless visual motion display). Each dot subtended a visual angle of $0.03^{\circ}-0.05^{\circ}$ (while the physical size of the dots on the screen was constant, the distances between the different dots varied because of the large size of the screen). The dots did not form a density gradient. Therefore, there were no static depth cues, and the only moving depth cue was motion parallax. The stimuli were the same as those used by Seno et al. (2010).

\subsection{Procedure}

All participants documented and regulated their sleep schedules for one week prior to the study. The participants did not consume caffeine or alcohol for three days before the experimental day. The ten participants reported no abnormal sleep behaviors.

We conducted five experiments from 9 - 10 AM, 12 PM - 1 PM, 3 PM - 4 PM, 6 PM - 7 PM, and 9 PM - 10 PM. We conducted five trials (about 5 minutes each) for each participant in each experimental session. The order of the 10 participants was pre-determined randomly. All participants stayed in two rooms that had constant room temperature $\left(25^{\circ} \mathrm{C}\right)$ and the constant illumination and brightness $(1000 \% \pm 5 \%$ lux $)$ from 9 AM to 9 PM and were never allowed to go any other place except for the toilet.

The participants were instructed to press a button when they perceived self-motion. The instructions were as follows: "Please press the button when you perceive forward or backward self-motion. Please keep the button depressed for as long as your experience of self-motion continues. If such a decision becomes difficult or if your perception of self-motion disappears, please release the button". We were very careful to keep the participants naive as to the purpose of our experiment because vection has been found to be modulated/biased by experimenter instructions and demands (e.g. Lepecq, Giannopulu, \& Baudonniere, 1995; Palmisano \& Chan, 2004). We also ensured that the participants received sufficient practice in pressing the button before they completed the actual experimental trials.

At the end of each trial, the participants were asked to rate the subjective strength of vection via magnitude estimation. They were told that their estimated values should range from 0 (no vection) to 100 (very strong vec- 
tion). While we did not use a standard stimulus for this magnitude estimation, we have used this exact method successfully in several previous studies (e.g. Seno, Ito, \& Sunaga, 2009).

\section{Results and Discussion}

We found that the average latencies, durations, and magnitudes of vection were not modulated by the time of day at which the experimental sessions took place. A one-way analysis of variance revealed no significant main effects of the time of the session (latency, $\mathrm{F}(4,36)=0.69, p=0.59$; duration, $\mathrm{F}(4,36)=1.07, p=0.38$; magnitude, $\mathrm{F}(4,36)=0.12, p=0.97)$. The absolute values of the obtained latencies, durations, and magnitudes of vection were almost identical between the five time conditions (Figure 1). Thus, our data indicated that the time of day had no effect on vection.

Figure 2 shows the individual results for the 10 participants. It is apparent that even in each individual, the time of the session had no effect on the latency, duration, or magnitude of vection. Thus, we concluded that circadian rhythms did not affect vection strength.

As described in the introduction, vection can be easily modified by various factors. Physical burden (Seno, Abe, \& Kiyokawa, 2013), age (Shirai, Seno, \& Morohashi, 2013; Shirai et al., 2014; Haibach, Slobounov, \& Newell, 2009), mood (Sasaki et al., 2012), altitude of the experimental environment (Nishimura et al., 2014), microgravity (Young \& Shelhamer 1990; Mueller \& Kornilova, 1994; Allison et al., 2012), body posture (Nakamura \& Shimojo, 1998; Seno, 2014), stimulus meanings (Seno \& Fukuda, 2012; Ogawa \& Seno, 2014), and alcohol consumption (Seno \& Nakamura, 2013) are all known to alter the strength of vection. Despite the large number of factors that are known to modulate vection, we found that time, i.e. circadian rhythms, did not alter vection strength. This was a very unexpected result.

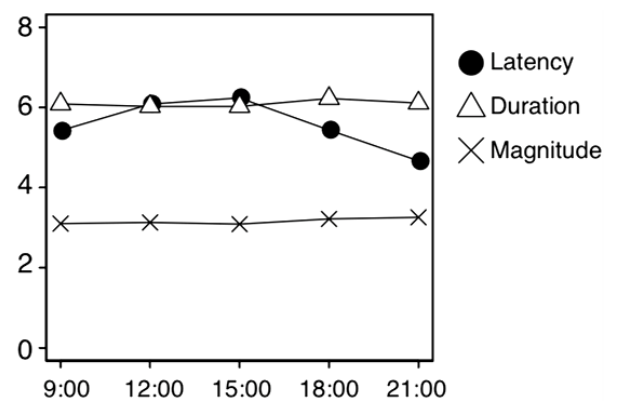

Figure 1. Latency, duration, and magnitude of vection according to the time of day. Duration and magnitude was divided by a value of 10 .
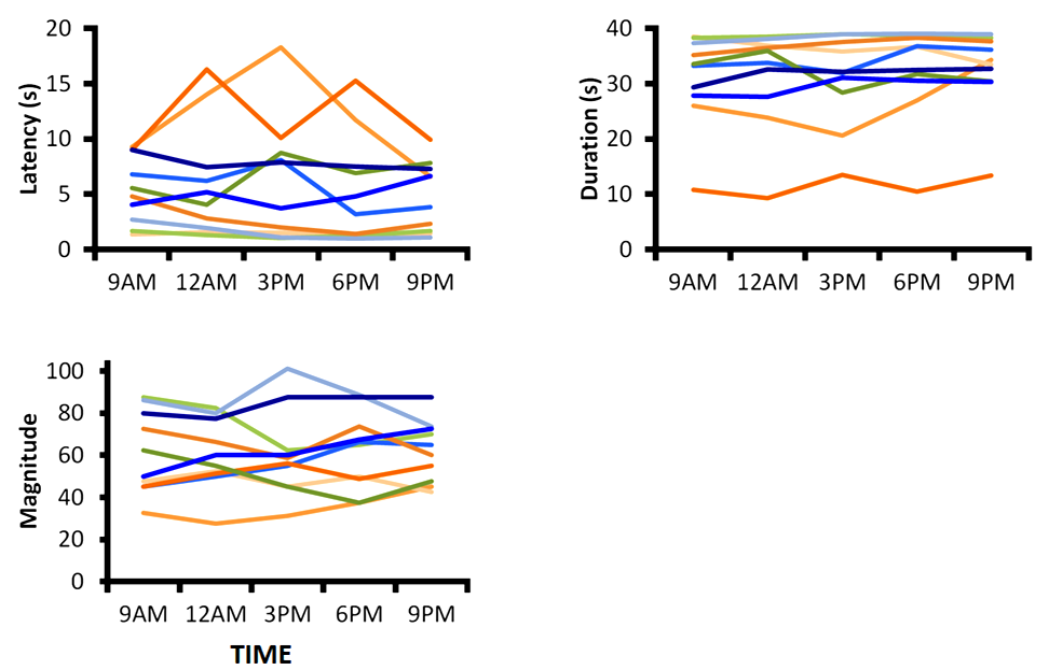

Figure 2. Individual latency, duration, and magnitude of vection results according to time of day. 
We speculate that the constant vection strength observed throughout the day and night is related to the risks associated with impaired visual perception. As visual perception is impaired during the night, it might be beneficial to maintain strength of motion (i.e., vection) regardless of the time of day. However, this aspect of visual perception requires further examination. Accordingly, we hope that our findings will be useful in future experimental design.

\section{Conclusion}

Our findings indicate that the circadian clock does not modulate human vision. Specifically, human vision does not appear to differ among morning, afternoon, and night. To the best of our knowledge, this finding has not been reported previously. As a result, future human vision experiments may not need to be restricted by the time of day.

\section{Acknowledgements}

This work was supported by the Program to Disseminate the Tenure Tracking System (MEXT, Japan) to TS; a Grant-in-Aid for Young Scientists (A), Japan, to TS and MO; and funding from the Inamori Foundation and Takeda Science Foundation to HI.

\section{References}

Allison, R. S., Zacher, J. E., Kirollos, R., Guterman, P. S., \& Palmisano. S. (2012). Perception of Smooth and Perturbed Vection in Short-Duration Microgravity. Experimental Brain Research, 223, 479-487. http://dx.doi.org/10.1007/s00221-012-3275-5

Araujo, D. F., Soares, C. S., \& de Almondes, K. M. (2013). Relation between Sleep and Visuospatial Skills in Students from a Public School. Estudos de Psicologia, 18, 109-116. http://dx.doi.org/10.1590/S1413-294X2013000100018

Aschoff, J. (1984). Circadian Timing. Annals of the New York Academy of Sciences, 423, 442-468. http://dx.doi.org/10.1111/j.1749-6632.1984.tb23452.x

Aschoff, J. (1998). Human Perception of Short and Long Time Intervals: Its Correlation with Body Temperature and the Duration of Wake Time. Journal of Biological Rhythms, 13, 437-442. http://dx.doi.org/10.1177/074873098129000264

Aschoff, J., \& Daan, S. (2009). Human Time Perception in Temporal Isolation: Effects of Illumination Intensity. Chronobiology International, 14, 585-596. http://dx.doi.org/10.3109/07420529709001449

Bonnet, M. (2002). Sleep Deprivation. In M. H. Kryger, T. Roth, \& W. C. Dement (Eds.), Principles and Practice of Sleep Medicine (pp. 53-71). Philadelphia, PA: W.B. Saunders Company.

Bougard, C., Lepelley, M. C., \& Davenne, D. (2011). The Influences of Time-of-Day and Sleep Deprivation on Postural Control. Experimental Brain Research, 209, 109-115. http://dx.doi.org/10.1007/s00221-010-2524-8

Brandt, T., Dichgans, J., \& Koenig, E. (1973). Differential Effects of Central versus Peripheral Vision on Egocentric and Exocentric Motion Perception. Experimental Brain Research, 16, 476-491. http://dx.doi.org/10.1007/BF00234474

Chee, M. W. L., \& Chuah, Y. M. L. (2007). Functional Neuroimaging and Behavioral Correlates of Capacity Decline in Visual Short-Term Memory after Sleep Deprivation. Proceedings of the National Academy of Sciences of the United States of America, 104, 9487-9492. http://dx.doi.org/10.1073/pnas.0610712104

Daan, S., Beersma, D., \& Borbely, A. (1984). Timing of Human Sleep: Recovery Process Gated by a Circadian Pacemaker. American Journal of Physics, 246, 161-178.

Dichgans, J., \& Brandt, T. (1978). Visual-Vestibular Interaction: Effect on Self-Motion Perception and Postural Control. In R. Held, H. W. Leibowitz, \& H. L. Tueber (Eds.), Handbook of Sensory Physiology (pp. 755-804). Berlin: Springer-Verlag.

Fischer, M. H., \& Kornmüller, A. E. (1930). Optokinetischausgelöste Bewegungswahrnehmung und Optokinetischer Nystagmus. Journal fürPsychologie und Neurologie (Leipzig), 41, 273-308.

Haibach, P., Slobounov, S., \& Newell, K. (2009). Egomotion and Vection in Young and Elderly Adults. Gerontology, 55, 637-643. http://dx.doi.org/10.1159/000235816

Held, R., Dichgans, J., \& Bauer, J. (1975). Characteristics of Moving Visual Scenes Influencing Spatial Orientation. Vision Research, 15, 357-365. http://dx.doi.org/10.1016/0042-6989(75)90083-8

Howard, I. P. (1982). Human Visual Orientation. Chichester: Wiley.

Kuriyama, K., Uchiyama, M., Suzuki, H., Tagaya, H., Ozaki, A., Aritake, S., Kameid, Y., Nishikawa, T., \& Takahashi, K. 
(2003). Circadian Fluctuation of Time Perception in Healthy Human Subjects. Neuroscience Research, 46, $23-31$. http://dx.doi.org/10.1016/S0168-0102(03)00025-7

Lepecq, J. C., Giannopulu, I., \& Baudonniere, P. M. (1995). Cognitive Effects on Visually Induced Body Motion in Children. Perception, 24, 435-449. http://dx.doi.org/10.1068/p240435

Lestienne, F., Soechting, J., \& Berthoz, A. (1977). Postural Readjustments Induced by Linear Motion of Visual Scenes. Experimental Brain Research, 28, 363-384.

Morofushi, M., Shinohara, K., \& Kimura, F. (2001). Menstrual and Circadian Variations in Time Perception in Healthy Women and Women with Premenstrual Syndrome. Neuroscience Research, 41, 339-344. http://dx.doi.org/10.1016/S0168-0102(01)00290-5

Mueller, C., Kornilova, L., Wiest, G., \& Steinhoff, N. (1994). Psychophysical Studies of Visuo-Vestibular Interaction in Microgravity. Actaastronautica, 33, 9-13. http://dx.doi.org/10.1016/0094-5765(94)90102-3

Nakajima, T., Uchiyama, M., Enomoto, T., Shibui, K., Ishibashi, K., Kanno, O., \& Okawa, M. (1998). Human Time Production under Constant Routine. Psychiatry and Clinical Neurosciences, 52, 240-241. http://dx.doi.org/10.1111/j.1440-1819.1998.tb01052.x

Nakamura, S., \& Shimojo, S. (1998). Stimulus Size and Eccentricity in Visually Induced Perception of Horizontally Translational Self-Motion. Perceptual and Motor Skills, 87, 659-663. http://dx.doi.org/10.2466/pms.1998.87.2.659

Nishimura, T., Seno, T., Motoi, M., \& Watanuki, S. (2014). Illusory Self-Motion (Vection) May Be Inhibited by Hypobaric Hypoxia. Aviation, Space, and Environmental Medicine, 85, 504-508. http://dx.doi.org/10.3357/ASEM.3812.2014

Ogawa, M., \& Seno, T. (2014). Vection Is Modulated by the Semantic Meaning of Stimuli and Experimental Instructions. Perception, 63, 605-615. http://dx.doi.org/10.1068/p7639

Ogawa, M., Matsumori, K., Seno, T., \& Higuchi, S. (submitted). The Deprivation of Sleep Might Enhance Vection.

Palmisano, S., \& Chan, A. Y. C. (2004). Jitter and Size Effects on Vection Are Robust to Experimental Instructions and Demands. Perception, 33, 987-1000. http://dx.doi.org/10.1068/p5242

Palmisano, S., Apthorp, D., Seno, T., \& Stapley, P. (2014). Spontaneous Postural Sway Predicts the Strength of Smooth Vection. Experimental Brain Research, 232, 1185-1191. http://dx.doi.org/10.1007/s00221-014-3835-y

Pöppel, E., \& Giedke, H. (1970). Diurnal Variation of Time Perception. Psychologische Forschung, 34, 182-198. http://dx.doi.org/10.1007/BF00424544

Riecke, B. E., Feuereissen, D., Rieser, J. J., \& McNamara, T. P. (2011). Spatialized Sound Enhances Biomechanically-Induced Self-Motion Illusion (Vection). Proceedings of the SIGCHI Conference on Human Factors in Computing Systems, Vancouver, 7-12 May 2011, 2799-2802.

Sasaki, K., Seno, T., Yamada, Y., \& Miura, K. (2012). Emotional Sounds Influence Vertical Vection. Perception, 41, 875-877. http://dx.doi.org/10.1068/p7215

Seno, T. (2013a). Social Inhibition of Vection. Psychology, 4, 619-621. http://dx.doi.org/10.4236/psych.2013.48088

Seno, T. (2013b). Music Enhances Vection. Psychology, 7, 566-568. http://dx.doi.org/10.4236/psych.2013.47081

Seno, T. (2014). Vection Is Not Determined by the Retinal Coordinate. Psychology, 5, 12-14. http://dx.doi.org/10.4236/psych.2014.51003

Seno, T., \& Fukuda, H. (2012). Stimulus Meanings Alter Illusory Self-Motion (Vection)—Experimental examination of the train illusion. Seeing \& Perceiving, 25, 631-645. http://dx.doi.org/10.1163/18784763-00002394

Seno, T., Abe, K., \& Kiyokawa, S. (2013). Wearing Heavy Iron Clogs Can Inhibit Vection. Multisensory Rresearch, 26, 569-580. http://dx.doi.org/10.1163/22134808-00002433

Seno, T., \& Nakamura, S. (2013). Alcohol Consumption Enhances Vection. Perception, 42, 580-582. http://dx.doi.org/10.1068/p7473

Seno, T., Ito, H., \& Sunaga, S. (2009). The Object and Background Hypothesis for Vection. Vision Research, 49, $2973-2982$. http://dx.doi.org/10.1016/j.visres.2009.09.017

Seno, T., Ito, H., \& Sunaga, S. (2010). Vection Aftereffects from Expanding/Contracting Stimuli. Seeing \& Perceiving, 23, 273-294. http://dx.doi.org/10.1163/187847510X532667

Shirai, N., Seno, T., \& Morohashi, S. (2013). More Rapid and Stronger Vection Can Occur in Elementary School Children than in Adults. Perception, 41, 1399-1402. http://dx.doi.org/10.1068/p7251

Shirai, N., Imura, T., Tamura, R., \& Seno, T. (2014). Stronger Vection in Junior High School Children than in Adults. Frontiers in Psychology, 5, Article 563. http://dx.doi.org/10.3389/fpsyg.2014.00563

Schmeider, E., Leweke, F. M., Stermemann, U., Weber, M. M., \& Emrich, H. M. (1996). Visual 3D Illusion: A SystemsTheoretical Approach to Psychosis. European Archives of Psychiatry and Clinical Neuroscience, 246, 256-260. 
M. Ogawa et al.

http://dx.doi.org/10.1007/BF02190277

Young, L. R., \& Shelhamer, M. (1990). Microgravity Enhances the Relative Contribution of Visually-Induced Motion Sensation. Aviation, Space, and Environmental Medicine, 61, 525-530. 